\title{
Un llamado de atención sobre ideas recibidas
}

\author{
A wake-up call about ideas received \\ Um chamado de atenção sobre ideias recebidas
}

\section{Claudia Gilman}

CONSEJO NACIONAL DE INVESTIGACIONES CIENTÍFICAS (CONICET), ARGENTINA

Investigadora del Consejo Nacional de Investigaciones Científicas,

CONICET. Doctora en Letras de la Universidad de Buenos Aires,

Argentina. Fue docente de literatura contemporánea en la Facultad

de Filosofía y Letras y de Antropología de las Élites en el doctorado

de la Facultad Latinoamericana de Ciencias Sociales. Es coautora de

Preciosas cautivas (narrativa) (Alfaguara, 1993) y autora de Entre la

pluma y el fusil. Debates y dilemas del escritor revolucionario en América

Latina (ensayo) (Siglo XXI, 2003) y Mejor mañana (poesía) (Paradiso

Ediciones, 2004). Correo electrónico: claudia.gilman@yahoo.com

Artículo de reflexión

Documento accesible en línea desde la siguiente dirección: http://revistas.javeriana.edu.co

El presente artículo es una versión del "Postfacio" de la segunda edición de mi libro, Entre la pluma y el fusil. Debates y dilemas del escritor revolucionario en América Latina. Buenos Aires: siglo XXI, 2012.

doi:10.11144/Javeriana.CL19-37.ulda 


\section{Resumen}

Este artículo reformula hipótesis canónicas sobre la identidad intelectual; la relación entre intelectuales, racionalidad y causas; la disponibilidad de los intelectuales para nuclearse, y otros aspectos más de la cuestión, tal como fueron expuestos en el libro Entre la pluma y el fusil. Aquí se trata de inscribir en una más larga duración la definición de los intelectuales, incorporando las nuevas condiciones para su intervención generadas por el pasaje de la grafosfera a la videoesfera y otras transiciones que han dado lugar a nuestro presente. Revisa hipótesis previas vinculadas con la conceptualización de una "familia" intelectual en la América Latina de los años sesenta y setenta confrontadas con el lugar ocupado por las mujeres, el papel de Ángel Rama y Emir Rodríguez Monegal en torno al llamado boom de la literatura latinoamericana e intenta dar cuenta de los desafíos actuales que permiten la formación de redes y asociaciones letradas.

Palabras clave: intelectuales; familia; cofradía; boom literario; pasión; racionalidad; clausuras; aperturas epocales

\section{Abstract}

This article reformulates canon hypotheses about intellectual identity, the relationship among intellectuals, rationality and causes, the availability of intellectuals to get together and other aspects of the issue, as explained in the book Entre la pluma y el fusil. The intention here is to record, in a definition with a longer duration, that of the "intellectuals," by including the new conditions for their intervention generated by going from the Grafosfera to the Videoesfera, and other transitions that have given rise to our present. It reviews previous hypotheses linked to the conceptualization of an intellectual "family" in the Latin America of the 1960s and 1970s vis-à-vis the place occupied by women, the role of Ángel Rama and Emir Rodríguez Monegal around the so-called "boom" of Latin American literature, and it tries to shed light on the current challenges that allow the creation of networks and educated associations.

Key words: Intellectuals; Family; brotherhood; literary Boom; rationality; closings; epoch openings

\section{Resumo}

Este artigo reformula hipóteses canônicas sobre a identidade intelectual, a relação entre intelectuais, racionalidade $\mathrm{e}$ causas, a disponibilidade dos intelectuais para se coligarem e outros aspectos da questão, tal como foram expostos em o livro Entre la pluma y el fusil. Aqui se trata de inscrever numa mais longa duração a definição de "intelectuais", incorporando as novas condições para sua intervenção geradas pela passagem da Grafosfera à Videoesfera e outras transições que têm lugar em nosso presente. Revisam-se hipóteses prévias vinculadas com a conceptualização de uma "família" intelectual na América Latina dos anos sessenta e setenta, confrontadas com o lugar ocupado pelas mulheres e o papel de Angel Rama e Emir Rodríguez Monegal em torno do chamado "boom" da literatura latino-americana, se tenta dar conta dos desafios atuais que permitem a formação de redes e associações letradas.

Palavras-chave: Intelectuais; família; confraria; boom literário; paixão; racionalidade; clausuras; aberturas epocais

RECIBIDO: 1 DE MAYO DE 2014. EVALUADO: 23 DE MAYO DE 2014. DISPONIBLE EN LÍNEA: 15 DE ENERO DE 2015

\section{Cómo citar este artículo:}

Gilman, Claudia. "Un llamado de atención sobre las ideas recibidas". Cuadernos

de Literatura 37 (2015): 102-114. doi:10.11144/Javeriana.CL19-37.ulda 
"¿Acaso no son un signo, todos esos intelectuales, venidos de todos los rincones del horizonte, reunidos por una idea?"

EN L O QUE sigue, resumiré algunas de las hipótesis históricas y funcionales por las que se identifican los intelectuales, esos hombres "reunidos por una idea". Se trata de hipótesis que han nublado otras constataciones realizadas con posterioridad: los hombres con disposiciones intelectuales han existido, sin duda, en todas las sociedades: incluso las culturas analfabetas albergaban individuos capaces de ocuparse de los problemas colectivos. Los grupos humanos se desarrollan si encuentran escenarios institucionales adecuados para los intercambios eidéticos y cuentan con al menos un círculo de personas a las cuales dirigirse. Suele proponerse que las condiciones de emergencia del estrato intelectual fueron favorecidas con el colapso de la sociedad medieval y los movimientos que fragmentaron la autoridad unificada de la Iglesia. Grupos religiosos, poderes seculares y sistemas políticos procuraron atraerse la lealtad de individuos que ya no estaban ligados a sus ataduras tradicionales: los llamados "hombres de ideas" encontraron el terreno favorable para constituir un estrato consciente de intelectuales con un ethos peculiar y un sentido de la vocación. La generalización de la cultura tipográfica fue crucial en el surgimiento de un grupo de intelectuales conscientes, capaz de contribuir a la formación de la opinión pública. En ese proceso confluyeron fenómenos como el aumento en el número y el peso específico de la clase media y las expectativas sobre el valor de la educación. La formación de una cultura de masas, que se inscribe en el desarrollo de características democráticas instauradas en el debate libre es otro factor que contribuye a la emergencia de esa microsociedad y será una característica constitutiva e intrínseca de su funcionamiento en redes asociativas.

En teoría, la asociación intelectual requiere una causa para dar sentido a los esfuerzos capaces de arrancar a los individuos del estado habitual de indiferencia general por los asuntos humanos que no sean los propios. Diversos escenarios institucionales favorecieron la conformación de asociaciones y grupos: el salón, el café, la sociedad científica, las revistas, el partido político y la bohemia. Igualmente importante fue el surgimiento de un extenso mercado de libros en el siglo XVIII y la aparición concomitante de libreros y editores como intermediarios entre el autor y el creciente público lector, para el cual la lectura se transformaba en el pasatiempo favorito mientras se conformaba la clase media. El contacto directo no siempre era necesario, porque las páginas impresas permitían muy bien el intercambio, 
especialmente en una época en la cual el público de las producciones intelectuales serias se había vuelto demasiado extenso y con más de una pequeña fracción.

Todas las hipótesis que versan sobre la identidad intelectual los colocan en una posición ligeramente separada respecto del resto de la sociedad, que le permite actuar según normas "propias" y supuestamente "racionales" de validez. Semejante participación común en un tipo de cultura agrupa a los miembros que la comparten. Y esa cultura se desarrolla a través del debate y el intercambio. La naturaleza misma de este último hace necesaria la asociación que es un lugar de convergencia, de apoyo mutuo y de extrapolación política y crea estructuralmente entre mentes próximas vínculos nuevos y de diferente naturaleza que los de la solidaridad escolar o profesional. En este sentido, hay una doble reproducción de la sociabilidad de la red intelectual: hacia adentro, en cuanto a las relaciones entre pares, y hacia afuera, en cuanto a su intrusión en la cultura y la sociedad.

Todas las hipótesis mencionadas dan por sentado que los intelectuales siempre se nuclean, inventan las redes y aprovechan las que existen, y crean también los ámbitos para su desarrollo, como un funcionamiento natural de su existencia. Las redes se basan ellas mismas en elementos difíciles de discernir. La simpatía y la amistad, por ejemplo y, al contrario, la rivalidad y la hostilidad, el rencor y la envidia, la ruptura y la desavenencia, desempeñan, como en toda microsociedad, un papel a veces decisivo. Esa sociabilidad puede entenderse de otro modo, porque las "redes" generan microclimas específicos y la palabra adquiere, desde esa perspectiva, un doble sentido de "redes" que estructuran y, a la vez, producen esos microclimas característicos de un determinado medio intelectual.

Existen hoy redes que no requieren la esforzada asociación voluntaria y están liberadas de toda demora en el espacio-tiempo. Sorprendentemente la extraordinaria e inerte posibilidad de reunión instantánea no produce comunidades intelectuales con vocación de ejercer un magisterio ideológico sobre otros, dado que no hay otros sin acceso a esas redes.

La realidad cuestiona la idea de que los intelectuales siempre se nuclean, inventan las redes y aprovechan las que existen, y crean también los ámbitos para su desarrollo, casi como parte de un funcionamiento natural. Y asimismo habrá que cuestionar que los intelectuales son, además, buenos, justos, altruistas y moralmente superiores al resto de las personas de a pie. Y que estos santos varones no se dejan llevar por las bajas pasiones. Sucede que, en cualquier época, los intelectuales siempre se han descripto ideológicamente a sí mismos con arreglo a sus particulares intereses. Estos pueden variar de una época a otra: no así la aspiración de los intelectuales de representarlos como los intereses generales del 
género humano. En otras palabras, las definiciones de los intelectuales son siempre autodefiniciones; sólo a ellos les interesa averiguar qué son y para qué sirven.

\section{La causa de la verdad y la justicia \\ Me convencí de que una revolución que tiene de su parte a todos los intelectuales es una revolución justa y necesaria. No puede ser otra cosa, no puede ser que centenares de escritores, poetas, pintores y músicos estén equivocados}

JULIO CORTÁZAR

Así describe y justifica Julio Cortázar su total adhesión a la Revolución cubana. Lo que resulta más llamativo es que Cortázar pueda creer que una Revolución que tiene de su parte a todos los intelectuales es, por ese hecho, justa y necesaria, ya que no le parece posible que centenares de escritores, poetas, pintores y músicos estén equivocados. $\mathrm{Y}$, sin embargo, este acto de auténtica fe se funda en una tradición que predica que los artistas e intelectuales son, por el hecho de ser lo que son, garantes de la objetividad, la ética y la justicia. En otras palabras, que encarnan una moral y una ética de la verdad y la justicia que debe considerarse auténtica, sincera y "verdadera". Ese acto de fe en sus "iguales" evoca el sustrato dogmático y eclesiástico del que es un desarrollo la "secularización". La creencia en los pares es más convincente que la de las masas, ante las cuales es conocida la posición de Cortázar y sus iguales. El fenómeno del peronismo ha mostrado también unidos a los intelectuales argentinos. No sólo a ellos: esas valoraciones de los llamados "populismos" son comunes a la intelectualidad "universal". El liderazgo en Cuba inicia relecturas letradas de esos fenómenos. Para no ser injusta ni cínica con los datos de la historia reciente muchos intelectuales militaron activamente por el advenimiento y triunfo de la revolución latinoamericana, tercermundista, socialista o nacionalista de manera desinteresada. Como contrapartida, a muchos de los famosos novelistas y críticos que se nuclearon en defensa de la Revolución Cubana aquella adhesión les resultó beneficiosa. Recibían trato de estadistas, eran escuchados y se tomaban en cuenta sus opiniones. ¿Serían ellos, acaso, los primeros filósofos que gobernarían una República, para envidia de Platón? Desfiles, actos públicos, ágapes difundidos en imágenes o textos los mostraban codo a codo con los héroes del momento. Las condiciones de la fama y la celebridad dependían todavía del concurso de las letras. 


\section{¿Familia o cofradía?}

"Nosotras (las mujeres) éramos las esclavas, ellos los intelectuales"

Otra cuestión importante que hace falta resaltar: categorías tales como "Hombres de ideas" o "intelectuales" son categorías que sólo pueden aplicarse (y así se lo hace, aunque no sea de manera muy explícita) a varones. En todo caso, la secularización describe el proceso inicial por el que un hombre de Iglesia abandona los hábitos. Resulta sorprendente que, en la época, mientras el futuro anunciaba el nacimiento de un hombre nuevo, una nueva mujer se encontraba disponible y ya nacida. Sin contar con que, además, desde comienzos de siglo mujeres de ciencia encabezaban los descubrimientos más importantes de sus disciplinas haciendo ciencia de primer nivel (Un ejemplo: Marie Curie fue premio Nobel de física en 1903 junto a su esposo y volvió a serlo, esta vez sola, en 1911).

No se puede olvidar - mi tardía disculpa por no haberlo tenido en cuenta- que en los sesenta, otra de las "revoluciones" pronosticadas fue la sexual: surgían las condiciones por las cuales las mujeres ya había una nueva mujer en condiciones de podían controlar su propio cuerpo, su sexualidad y su agenda reproductiva.

La noción de campo intelectual no puede dar cuenta de la ausencia de mujeres a lo largo de las páginas de Entre la pluma y el fusil (2003). La "familia" intelectual, por lo tanto, hace de las mujeres el habitual borramiento, fruto tal vez del encandilamiento de la época por la épica viril. El empleo del término "familia" para referirme a una asociación deliberada, empírica y de vínculos estrechos en ámbitos decididamente domésticos, tal como se presentan a sí mismos autores "del boom" y también integrantes de revistas como es el caso de "Libre", debió haber sido cofradía o hermandad, puesto que sin lugar a dudas, sólo incluía varones.

La derrota de las expectativas revolucionarias a nivel mundial — derrota momentánea, puesto que los pronósticos son sólo una posibilidad y las clausuras pueden ser un espejismo, como lo fue el del "fin de las ideologías" en su momento-, la revolución que entonces se frustró se "cargó" también la de la nueva mujer, que no fue llamada a integrar sus filas, pese a que constituía la mitad del mundo. Sin dudas, las reivindicaciones que actualmente defienden los derechos de las minorías tienen antecedentes en las luchas de la época de los años sesenta-setenta, aunque más acá de las conquistas obtenidas, se impone decir que, en lugar de relajarse, los controles sexuales se redefinieron, el matrimonio se mantuvo como una opción mayoritaria, las uniones estables continuaron siguieron "garantizando" el marco ideal de la procreación e incluso las parejas homosexuales reivindicaron la estabilidad del vínculo y los derechos a formar 
una familia legítima. El mercado del sexo reforzó la dominación y la marginación de las mujeres, a quienes siguieron cargando con las tareas domésticas. Las expectativas albergadas por los activistas de la liberación sexual de los años sesenta quedaron limitadas. No se modificaron drásticamente las relaciones de poder en el capitalismo ni surgió una sociedad reconfigurada sobre nuevos principios políticos, derivados de una nueva moral sexual, como planteaba el optimismo de Wilhelm Reich o de Herbert Marcuse. Tampoco desaparecieron la iniquidad en las relaciones de pareja ni la discriminación a las mujeres. La ola liberal y progresiva de los años sesenta y setenta fue seguida de una etapa de reacción y conservadurismo (Cosse, 2010).

Para regresar precisamente a Pierre Bourdieu: el modelo recuerda que sigue vigente la ley fundamental de igualdad entre varones sobre la que se rige el honor: sólo es digno de honra el reconocimiento otorgado a un hombre (por oposición a una mujer), y sólo un hombre es digno rival en la lucha por el honor. "El pro patria mori nunca es sino el límite de todas las maneras, más o menos nobles y reconocidas, de morir o vivir por causas o fines universalmente reconocidos como nobles, es decir, universales" (Bourdieu, 2000). La virtud y la fuerza (vis y vir) son atributos que el hombre no comparte en la generalización de la "humanidad". No habiendo palabras, es difícil hacer entrar lo que se excluye y es difícil reparar en lo que se omite.

\section{Dos para el boom: made in Uruguay}

"Hasta el momento, cada literatura tenia su historia singular. Sin duda, no se desarrollaba sin contactos con el mundo exterior, pero lo más frecuente era que las influencias se manifestaran de manera lenta, tardía, parcial, irregular. Hoy, gracias a la multiplicidad de las traducciones, al acortamiento de las distancias, al ritmo precipitado que preside el crecimiento del volumen de las relaciones humanas de toda especie (incluyendo la propagación de las ciencias y las técnicas, de las ideas y modos de vivir, las influencias, incluso en literatura, al menos a causa del impacto amplificador y simplificador de la prensa, el cine, la radio y la televisión se ejercen de manera inmediata, masiva, constante, burlándose de las antípocas y de todo contraste de climas o costumbres, de tradición o de situación"

ROGER CAILLOIS, 1961

En una carta enviada por correo postal, fechada el 9 de mayo de 2000, Tulio Halperin Donghi consigna generosos comentarios al manuscrito de mi tesis doctoral y me cuenta que la lectura le sirvió para comprender por qué "aunque Ángel Rama decía que no entendía por qué Emir le seguía teniendo tanta rabia, las razones le sobraban". 
Se podrían llenar volúmenes consignando algunos disensos tan patéticos como improductivos en los que Ángel Rama y Emir Rodríguez Monegal se combatieron mutuamente, no siempre por causas ideológicas ni políticas. Con gran frecuencia mi trabajo registró las peripecias del enfrentamiento entre ambos críticos, priorizando la disputa política e ideológica como factor decisivo de la rivalidad, y puntualmente en función de las discusiones que entablaron en torno a la revista Mundo Nuevo, fundada por el propio Monegal en París, en 1966, y considerada punta de lanza de la CIA para neutralizar o impedir la adhesión de los intelectuales a la causa revolucionaria cubana. Pero lo cierto es que antes de odiarse por eso, se odiaron por casi todo lo que puede interponerse entre dos personas. La apasionada y sistemática rivalidad entre ambos, que condicionó su juicio crítico al punto de sostener posiciones antagónicas sobre cualquiera de los temas que abordaban, y que permitieron que la duda metódica sobre la racionalidad de sus posiciones encuentre un sitio razonable. Ya en 1959, ambos determinaban que era inconciliable lo que los separaba. Convocados a debatir en una emisión radial sus pareceres sobre el tema Evasión y arraigo en Borges y Neruda, Rodríguez Monegal había afirmado que lo separaba de Rama "algo inconciliable", "como la famosa disputa sobre si era mejor el invierno que el verano", ante lo cual Rama confirmaba que la discrepancia entre ambos era, en efecto, "inconciliable", manera incluso hiperbólica, la historia total de la filosofía ha sido analizada como el resultado de la rivalidad de los filósofos.

Tratando de encontrar las "causas sociales" de la filosofía, Randall Collins (1989) argumenta que la existencia de diversas escuelas es esencialmente causada por la rivalidad entre los maestros. Sin radicalizar esa hipótesis y consciente de la complejidad de ciertos procesos, no deja de ser interesante tener en cuenta cómo las cosas humanas en general siempre están presentes en las construcciones de agrupamientos o redes colectivas. Uno de los casos ejemplares durante el período de elaboración de las redes latinoamericanistas de los años sesenta y setenta ha sido, sin duda, el de los dos críticos uruguayos, que en muchos ámbitos se opusieron y en otras tantas cuestiones se superpusieron, en su rol de intelectuales referentes de América Latina, durante un periodo fundamental del desarrollo de nuestras letras. Efectivamente, los inventores del canon de la nueva novela latinoamericana fueron capaces de crear desde el Uruguay redes letradas antagónicas, basadas en disputas ideológicas, claro está, pero cuyo origen se remonta también a sentimientos de mutuo desagrado o competencia por legitimar su propia posición y deslegitimar la del otro.

En Entre la pluma y el fusil, no se señalaba pero se dejaba ver lo profundo de las convicciones y los prejuicios que compartían Rama y Monegal, y gran 
parte de la veracidad de lo que se consigna se funda en esos acuerdos tan inverosímiles que deben ser ciertos a pesar de la voluntad de disenso que animó desde siempre y hasta el fin, la actividad de ambos críticos. Críticos que, desde el pequeño Uruguay, legislaron y pontificaron sobre obras literarias y escritores: ambos son los responsables de hacer estallar en la onomatopeya "boom", esa categoría nada categorial. Rodríguez Monegal usa la expresión pero es Rama quien durante todo el año 1967 se refiere al "boom" que años después repudiaría, como consta en las páginas literarias del semanario uruguayo Marcha, en donde es Director y sucesor de Monegal.

No hubo promotores más activos del "boom", entre cuyo apogeo y caída transcurrió muy poco tiempo, que Rama y Rodríguez Monegal. Los autores que no hubieran contado con el apoyo de ambos - como sí lo obtuvieron Vargas Llosa, García Márquez, Carlos Fuentes, Juan Carlos Onetti, Guillermo Cabrera Infante y Julio Cortázar (que probablemente no le gustaba mucho a ninguno), para mencionar algunos-, no se consagraron ante la crítica o los lectores que compraban libros. En este punto contrariaron la vieja costumbre adquirida de no coincidir nunca en nada, mal que les pesara a ambos. Ambos fueron necesarios. Los autores consagrados contaron, siempre, con el visto bueno de los dos críticos uruguayos.

Para que hubiera intelectuales como los que se nuclearon en la "época de los sesenta y setenta", era preciso que hubiera ciertas condiciones materiales. Así como los ejecutivos podían ir, como dice la canción de María Elena Walsh, del sillón al avión, también los intelectuales tenían a su disposición los vuelos frecuentes, que les facilitaban ir del avión a la revolución. Naturalmente, también debían experimentar el deseo y el deber de actuar como comunidad. Los intelectuales de los años sesenta no tuvieron que competir con la televisión ni con crecientes masas de colegas que, promoción tras promoción, egresaban de las universidades con títulos de humanistas y reinterpretaban el tópico de la conciencia crítica en términos disciplinarios que más tarde fundaron el saber que se denomina "crítica". Una "crítica" que, en muchos casos, se presenta como un modo de impugnación de lo existente aunque lo existente no parezca advertirlo ni dejar de ser lo que es.

\section{Transformaciones en revistas y una nueva época}

Las revistas político-culturales que animaban la vida intelectual en los años sesenta, y lo comunitario de esa vida, se discontinuaron, como la enseñanza de la dactilografía. En cambio subsisten las pasiones de rivalidad y odio que enfrentaron a Rama y Monegal: no se las puede hacer desaparecer por decreto o ignorando que han existido y existen todavía y que animan a todos los hombres y 
mujeres, incluidos, naturalmente, a los intelectuales. El igualitarismo declarativo se convirtió en fundamento de la producción de teorías e impugnaciones contra otras teorías. Y toda práctica, incluso la menos concernida en cuestiones políticas o ideológicas, fue juzgada o absuelta según su autoritarismo. Sin embargo, en aparente paradoja y como segundo señalamiento, el sistema de organización de la ciencia se burocratizó. Aunque nos resulte un requerimiento normal, recién a partir de la segunda posguerra el referato se institucionalizó hasta convertirse en el elemento de legitimación de una publicación, precisamente cuando las revistas culturales y político-culturales de alcance masivo comenzaron a declinar y fueron reemplazadas por otras de difusión muy restringida, donde circula el nunca más célebre "supuesto saber", custodiado por "evaluadores".

Los intelectuales de los años sesenta no tuvieron que competir con la televisión ni con crecientes masas de colegas que, promoción tras promoción, egresaban de las universidades con títulos de humanistas y reinterpretaban el tópico de la conciencia crítica en términos disciplinarios que más tarde fundaron el saber que se denomina "crítica" y que, en muchos casos, se presenta como un modo de impugnación de lo existente aunque lo existente no parezca advertirlo ni dejar de ser lo que es.

Alain Badiou denomina "segunda restauración" al período que se inicia a mediados de los años setenta, al tiempo que subraya la victoria del capitalismo globalizado (Badiou, 2005). La experiencia sugiere, sin embargo, que la realidad es lo suficientemente opaca como para desmentir nuestros diagnósticos, y más lo es el futuro para tolerar nuestros pronósticos. Los espacios geográficos que Badiou identifica con el mundo y los acontecimientos que merecen su atención se encuentran geográficamente limitados. La centralidad de Cuba, imposible de olvidar a menos que se sepulte lo que significó en 1962 la crisis de los misiles o el impacto de las entusiastas masas de chinos coreando canciones militantes de Cuba, en castellano kordon. Es difícil enterrar de una vez al Che Guevara y no mencionarlo como parte inescindible del Siglo o de nuestro pasado reciente. Es importante señalarlo porque para cambiar al mundo hay que saber dónde queda. Y a dónde va más allá de nuestras locaciones, en particular si nos situamos en el cómodo mundo desde donde se ve bastante poco de la extensión del planeta. Tal vez estemos asistiendo a una larga pero consistente órbita histórica en torno a la geografía que originó las principales religiones monoteístas.

Por otra parte, entre las transformaciones de los últimos cuarenta años, la de las tecnologías de la palabra ha literalmente revolucionado el mundo. Inmensas mayorías no sólo saben leer y escribir sino que leen y escriben o, más bien, escriben. La distancia entre intelectuales y no intelectuales era inherente a la noción 
misma de intelectual. Abolida esa distancia, se hace difícil pensar en tareas propiamente intelectuales, parecidas a las registradas en otros momentos del pasado.

La carrera académica y la devaluación de los títulos de grado provocada por el incremento de los graduados y las matrículas universitarias multiplicaron las áreas disciplinarias y los objetos de estudio, que se han vuelto tan poco relevantes que pueden ser reclamados como propios por todos los miembros de la comunidad. El derrape de la revista Social Text, que, tras la rutinaria revisión por pares, publicó "Transgressing the Boundaries: Towards a Transformative Hermeneutics of Quantum Gravity", el paper-ficción de física y psicoanálisis de Alain Sokal, es emblema de la capitulación del pensamiento ante todo lo que el pensamiento no comprende ni se propone comprender. La generalizada convicción de que la ciencia no tiene nada que ver con la verdad se expresó y continúa haciéndolo en la inmensa producción de trabajos dedicados a explicar por qué es preciso ser relativista a tal punto que ha perdido validez el postulado de que no sabemos si una teoría o hipótesis es verdadera al menos sí podemos saber si es falsa.

Las acciones humanas reales no siempre confirman la confianza en la racionalidad del Homo Sapiens; más bien se requiere un esfuerzo, como "saltar" para ir contra la fuerza de la gravedad, ya que el "caso humano" tira fuerte hacia la animalidad. A diferencia de los pompeyanos que padecieron la primera erupción del Vesubio y que no volverían a construir sus hogares al lado del volcán, los sabios del presente emplazan centrales nucleares en zonas regular y sistemáticamente afectadas por terremotos y tsunamis, como saben tanto los científicos como las personas con un mínimo de información. De modo que no es nada extraordinario que suceda lo que se sabía que podía suceder y que ya había sucedido. Lo extraordinario es que el saber no haya servido para nada. El hombre puede ser un animal racional pero no está obligado a serlo. Cuesta imaginar semejante irracionalidad en las acciones humanas deliberadas, conscientes y con consecuencias previsiblemente fatales. Ni la ignorancia, ni el idealismo ni la ideología pueden considerarse explicativos de tamaña insensatez. Basta consultar en Wikipedia para enterarse de que la geografía "Japón" se encuentra en medio del altamente sísmico cinturón de fuego del Pacífico. Registra terremotos desde comienzos del siglo XVIII y en los últimos pocos años sufrió más de cinco. ¿¿ónde está el homo sapiens? En simultáneo con las críticas cada vez más crípticas que se benefician con el retroceso de las exigencias de veracidad se generalizan objeciones al pensamiento fundadas en cucos como el binarismo, el biologismo y otros reduccionismos académicos y las causas se convierten en declaraciones de principios que impiden una práctica fundada esos principios, no siempre inconciliables. Es difícil hacer coincidir el derecho de una ballena con el de los habitantes de 
Ruanda. Menos difícil es abogar por una racionalidad más radical, por el abandono de la glosa y el comentario y que se dispense al investigador de ingresar al campo del conocimiento sin cargar la herencia de autoridades jerárquicas, las prohibiciones meramente protocolares o fobias teóricas de miedos ajenos.

Hacia fines de los años setenta, Marshall Mc Luhan observaba el generalizado desinterés de las personas por comprender el mundo y la preocupación por definir si algo es bueno o malo para juzgarlo (Mc Luhan, 1974). La red Facebook satisface automáticamente el deseo judicativo al promover el sistema de opciones "me gusta" o "no me gusta": a cuarenta años de identificado el síndrome de subir o bajar el pulgar ante cualquier cosa, ese síndrome se ha expandido colosalmente en el soporte de lo "escrito". En un mercado regulado por reglas que — sabemos- no favorecerán la producción ni la circulación colectiva de nuevos, mejores y más conocimientos, el toque de reunión se ha vuelto toque de queda. $\mathrm{i}$ Estaremos a la altura de los desafíos que plantea hoy la formación de redes, que se supone sencilla? $\dot{\mathrm{C}}$ Aprovecharemos los canales de los que disponemos, como lo hicieron quienes en los siglos XIX y XX sortearon obstáculos ahora inexistentes y pusieron en juego energías, recursos y voluntades para crear las comunidades en las que se buscó pensar, dialogar, valorar lo común, integrar, conocer, intercambiar, colaborar? Ojalá.

Para que el tipo de asociación fuera posible en la época, eran necesarias ciertas condiciones materiales y, por supuesto, el deseo o la necesidad de estructurar un colectivo tras un acontecimiento. Entre aquella época y el presente, sucedió que la evolución de las tecnologías fundadas inicialmente en la escritura desarrollaron por sí mismas las condiciones de la asociación y, paradójicamente, han dificultado la sociabilidad entre intelectuales que estudian esas redes pero no las utilizan como en el pasado. Los "cristales de masa" del presente se forman gracias a la existencia de canales mecánicos disponibles para la mayoría de los individuos que tienen acceso a las redes sociales y que, a través de ellas, sin la mediación de ninguna conciencia, tienen la capacidad mercurial de organizarse y, eventualmente, también derrocar a un dictador. Las "causas" o "toques de reunión" bien pueden haber estado interpelando largamente, pero sólo las condiciones mecánicas facilitan el agrupamiento efectivo y la conjunción de fuerzas y voluntades. El proceso de formación de la opinión pública, que estuvo en manos de letrados hasta hace muy poco, ¿ya no requiere de esas voces? ${ }_{\mathrm{i}} \mathrm{O}$ ya no las permite? Kant podía preguntarse por el sentido de su actualidad porque escribía sobre ella cuando la actualidad le era contemporánea. ¿Dónde, hoy, puede pensar su actualidad un intelectual-académico que debe esperar años para que el proceso de revisión por pares publique sus escritos, que por fuerza tienen que ser inactuales, puesto que quien escribe conoce los protocolos de la espera y no 
puede apostar a que sus palabras constituyan una intervención sobre el presente? La idea de que lo nuevo es un valor absoluto ha logrado incluso que se promocionen los productos de consumo masivo sobre la base de su novedad, incluso cuando nadie explique por qué se predica de ellos que son nuevos. $\mathrm{O}$ cuando su supuesta novedad sea una superchería evidente: se argumenta, en público, sin que nadie se oponga, que tal o cual producto para lavar la ropa supera a los otros, que pasan a ser "tradicionales", por contener "moléculas de extra limpieza". No existen tales moléculas y es extrañísimo que nadie se interese en evitar que se propaguen argumentos falsos con tal de vender jabón en polvo. Sorprende que estén tan separados el mundo de la ciencia, el del marketing y el sentido común, que no siempre es el peor de los sentidos.

En su "Teoría racional de lo bello", Baudelaire, un indiscutible defensor de lo nuevo, para defender lo nuevo tiene que establecer que "lo actual" es la mitad del arte. La otra mitad, eterna e inmutable, si hacemos los cálculos desde Baudelaire hasta el presente, se ha vuelto más grande y ha dejado de ser sólo una mitad. Incluye, por otra parte, al mismo Baudelaire.

El mundo, para Mallarmé, bien podía ser algo que estaba hecho para terminar en un Libro. Es razonable que uno de los más eminentes poetas de la generación que se alfabetizó masivamente en un mundo tan dominado por la presencia excluyente de lo escriturario pensara de ese modo.

Nada ha terminado. Somos nosotros los que ponemos fin a nuestras cosas y a nuestras periodizaciones, no la historia. La palabra "fin" no pone fin ni el fin se limita a ser una palabra. Como recuerda Braudel y sabemos por experiencia (1958), el hombre sigue estando, como al principio, prisionero de la geografía y cautivo del clima. Por ahora.

\section{Obras citadas}

Badiou, Alain. El Siglo. Buenos Aires: Manantial, 2005.

Baudelaire, Charles, "Le Beau, la Mode et le Bonheur", "Le peintre de la vie moderne", Le Figaro, 1863.

Braudel, Fernand. "Histoire et Science Sociale: La Longue Durée" (1958) Annales E.S.G., 13: 4 (Oct.-Déc. 1958): 725-753.

Caillois, Roger. Man, Play, and Games. Chicago: University of Illinois Press, 1961.

Collins, Randall. "Toward a theory of intellectual change. The social causes of philosophies", Science, Technology and Human Values, 14, 2 (1989): 107-140. Impreso.

Cosse, Isabella. Pareja, sexualidad y familia en los años sesenta: una revolución discreta en Buenos Aires. Buenos Aires: Siglo XXI, 2010. Impreso.

Mc Luhan, Marshall. La cultura es nuestro negocio. México: Diana, 1974. Impreso. 